Walker, L. E., and J. M. Marzluff. 2017. Reticence or vigilance at the nest: a cruel bind for the endangered Black-capped Vireo. Avian Conservation and Ecology 12(1):1. https://doi.org/10.5751/ACE-00923-120101

Copyright $(C 2017$ by the author(s). Published here under license by the Resilience Alliance.

Research Paper

\title{
Reticence or vigilance at the nest: a cruel bind for the endangered Black-capped Vireo
}

\author{
Lauren E. Walker ${ }^{1}$ and John M. Marzluff ${ }^{1}$ \\ ${ }^{1}$ School of Environmental and Forest Sciences, University of Washington, Seattle, Washington, USA
}

\begin{abstract}
Breeding birds vocalize to find mates and establish and defend territories, but these same critical communications may also attract predators or brood parasites, placing birds in a cruel bind. Although vigilant birds may better maintain social relationships with mates and neighbors through frequent vocalizations, reticent birds may reduce risk to their nests by being relatively quiet and making infrequent vocalizations. Selection for vocalization patterns that minimize brood parasitism might be particularly strong for birds that are unable to fledge both their own young and the parasite. Temporal plasticity in the frequency of vocalizations near nests, however, may allow birds to balance trade-offs and optimize nest-defense strategies. The Black-capped Vireo (Vireo atricapilla) is an endangered songbird that faces intensive brood parasitism in areas where Brown-headed Cowbirds (Molothrus ater) are present. Vireo nests that produce cowbird fledglings always fail to fledge vireo young. We recorded vocalizations at vireo nests across three nesting stages (building, laying, and early incubation) and three periods of the day (morning, midday, and evening) and compared vocalization frequency with eventual depredation or parasitism fate as well as local cowbird density to test two hypotheses. The predator-attraction hypothesis predicts that predators will be attracted by frequent vocalizations, whereas cowbirds will parasitize nests with relatively quiet parents and less predation risk; thus, vireos will experience trade-offs between reticence and vigilance in mediating specific risks. The parasite-assessment hypothesis predicts that vireos will become more secretive as local cowbird densities increase. Vireo vocalization response to nest predation and parasitism risk interacted with nest stage, and we found little evidence of risk mediation through vocalizations except during the building stage. Vireos, however, did benefit overall by optimizing temporal patterns in vocalizations. Vireo nests were less likely to be depredated or parasitized if males vocalized most during laying and least during the middle of the day. Birds vocalized more during the midday and less during the laying period when local cowbird densities were higher, however, perhaps demonstrating limited plasticity in social communication.
\end{abstract}

\section{Réticence ou vigilance au nid : un dilemme cruel pour le Viréo à tête noire, en voie de disparition}

RÉSUMÉ. Les oiseaux nicheurs chantent pour trouver un partenaire, et pour établir et défendre un territoire, mais ces mêmes vocalisations essentielles peuvent aussi attirer les prédateurs ou les parasites de couvées, ce qui place ces oiseaux dans une situation très difficile. Même si les oiseaux « vigilants » maintiennent peut-être mieux les relations sociales avec leur partenaire et les voisins grâce à des vocalisations fréquentes, les oiseaux « réticents » réduisent peut-être le risque à leur nid en demeurant relativement tranquilles et en vocalisant peu fréquemment. La sélection en faveur d'une stratégie de vocalisation qui minimise le parasitisme pourrait être particulièrement forte chez les oiseaux qui sont incapables d'élever leurs propres jeunes jusqu'à leur envol en même temps que ceux du parasite. Toutefois, la plasticité temporelle de la fréquence des vocalisations près des nids permet peut-être aux oiseaux de prendre en compte les contraintes et d'optimiser les stratégies de défense du nid. Le Viréo à tête noire (Vireo atricapilla), un passereau en voie de disparition, subit du parasitisme intense dans les régions où le Vacher à tête brune (Molothrus ater) est présent. Les nids de viréo qui produisent des jeunes vachers à l'envol ne réussissent jamais à mener des jeunes viréos à l'envol. Nous avons enregistré les vocalisations aux nids de viréos à trois stades de nidification (construction du nid, ponte et début de l'incubation) et à trois périodes du jour (matin, mi-journée et soir). Nous avons ensuite comparé la fréquence des vocalisations et le sort éventuel du nid (prédaté ou parasité), de même que la densité locale de vachers afin de tester deux hypothèses. L'hypothèse de " l'attraction du prédateur » prédit que les prédateurs seront attirés par les vocalisations fréquentes, tandis que les vachers vont parasiter les nids dont les parents sont tranquilles et qui risquent moins d'être prédatés; de cette façon, les viréos vont faire des compromis entre la réticence et la vigilance, en modulant des risques spécifiques. L'hypothèse de « l'évaluation du parasitisme » prédit que les viréos vont devenir de plus en plus discrets à mesure que la densité locale de vachers va augmenter. La stratégie de vocalisation des viréos en fonction de la prédation du nid et du risque de parasitisme a varié selon le stade de la nidification, et nous n'avons pas vraiment observé de modulation du risque au moyen des vocalisations, sauf durant la construction du nid. Cependant, les viréos ont globalement tiré profit de la situation en optimisant les stratégies temporelles de vocalisations. Les nids de viréos étaient moins susceptibles d'être prédatés ou parasités si les mâles vocalisaient le plus au moment de la ponte et le moins en mi-journée. Toutefois, les oiseaux vocalisaient plus en mi-journée et moins durant la période de ponte lorsque les densités locales de vachers étaient élevées, ce qui montre peut-être une plasticité limitée dans les communications sociales.

Key Words: Black-capped Vireo; Brown-headed Cowbird; Molothrus ater; nesting behavior; parasitism; Vireo atricapilla; vocalizations 


\section{INTRODUCTION}

Animal communication is critical for locating conspecifics, establishing territories, obtaining a mate, and coordinating social activities (Bradbury and Vehrencamp 2011). Breeding birds in particular use songs and calls to attract mates and repel rivals (Catchpole 1987, Kroodsma and Byers 1991), and song quality can directly contribute to mating success as well as mate quality (Nowicki and Searcy 2005). Additionally, vocalizations of a particular frequency or quality, such as scold calls, may attract neighboring birds for group defense or social learning (Cornell et al. 2012). Frequent or loud vocalizations near the nest (i.e., vigilance), however, may also cue nest predators or brood parasites to the location of the caller's nest (McLean et al. 1986, Clotfelter 1998, Banks and Martin 2001). Avian brood parasites rely on pairs of other breeding birds to incubate their eggs and raise their young, often imposing reproductive and energetic costs on their hosts (Rothstein 1975, Payne 1977). Thus, although defense strategies could favor increased communication between pairs, risk of predation or parasitism might induce alternative selective pressures on vocalization near the nest. Nesting birds might benefit from secretive behavior with fewer vocalizations (i.e., reticence) in proximity to their developing clutch (Skutch 1976, Marzluff and Balda 1992, Lima 2009). The need to remain attentive and coordinated without attracting undue attention puts nesting birds in a cruel bind (Trivers 1972). Natural selection presumably solves this bind through the influence of parental actions that benefit the development of their young while enabling detection and appropriate responses to the threats of parasites and predators.

The strength and direction of selection on vocalization frequency during the breeding season may depend on a variety of community features that define the trade-offs between reticence and vigilance, including the predator guild or the presence of brood parasites such as the Brown-headed Cowbird (cowbird; Molothrus ater). Avian predators and brood parasites cue in to auditory and other behavioral signals to locate nests (McLean et al. 1986, Uyehara and Narins 1995, Clotfelter 1998, Banks and Martin 2001, Haff and Magrath 2011), whereas many mammalian or reptilian nest predators are more reliant on olfaction (Conover 2007). For example, loud vocalizations by American Robins (Turdus migratorius) during the breeding season attract crows (Corvus sp.) (McLean et al. 1986), and begging calls by nestlings attract a wide variety of avian predators (Skutch 1976, McDonald et al. 2009, Haff and Magrath 2011). In a comparison of four songbird species, Banks and Martin (2001) also found that the frequency of cowbird parasitism increased among species with males that were more vocal and active near their nests during the nest-building period. By contrast, some species may benefit from remaining vigilant and actively defensive of their nests. Bell's Vireos (Vireo bellii) that vocalized more during nest building and incubation were parasitized less by cowbirds than relatively quiet pairs (Least Bell's Vireo, V. b. pusillus: Sharp and Kus 2006; Arizona Bell's Vireo, V. b. arizonae: Steckler and Conway 2012).

A temporal shift in vocalizations could allow for a combination of behavioral adaptations that would accommodate both sexual selection and natural selection to reduce parasitism or predation risk. That is, temporal flexibility may help nesting birds minimize the trade-offs between reticence and vigilance and more effectively navigate these two substantial risks. Cowbirds present a particularly challenging and unique threat to nesting songbirds because the risk they present at nests may shift throughout the nesting cycle. Cowbirds often locate nests while the host is building and generally return to parasitize the nest early in the morning during the host's laying stage (Scott 1991, Davies 2000, Banks and Martin 2001). In later nesting stages, however, cowbirds may also be nest predators, removing eggs or nestlings from unparasitized host nests to encourage the parents to renest (Arcese et al. 1996, Dubina and Peer 2013). Thus, depending on the local suite of brood parasites and nest predators, nesting songbirds may minimize parasitism or predation risk through stage-specific vocalization behaviors, e.g., being relatively secretive during building but vigilant in nest defense in laying or incubation stages. Likewise, many songbirds are able to adjust vocalizations to minimize interference from singing males of other species (Ficken et al. 1974, Barclay et al. 1985, Lougheed and Handford 1989) or in response to increases in urban noise (Warren et al. 2006, Fuller et al. 2007), and plasticity in the timing of social behaviors may also help some birds avoid temporally specific threats (Ghalambor and Martin 2000, Eggers et al. 2005). For example, in areas with high predator presence, Siberian Jays (Perisoreus infaustus) visited their nests less frequently during the afternoon, when their nest predators were more active, and compensated by making more frequent visits when predators were less active (Eggers et al. 2005).

The Black-capped Vireo (vireo; Vireo atricapilla) is an endangered songbird threatened by habitat loss as well as high rates of brood parasitism by cowbirds on their breeding grounds, which range from northeastern Mexico through Texas and southern Oklahoma (Graber 1961, Ratzlaff 1987, Grzybowski 1995). Management of vireo recovery to date has largely focused on the removal of cowbirds from vireo breeding habitat, creating several large, managed populations, including the Fort Hood Military Installation (Fort Hood) in central Texas (Kostecke et al. 2005, Cimprich and Cimprich 2015). Nest parasitism, however, continues to significantly contribute to the ongoing low reproductive rate of vireos in many areas without cowbird control (Walker 2015). Vireo nests are also susceptible to a broad suite of nest predators across the breeding range (Stake and Cavanagh 2001, Stake and Cimprich 2003, Conkling et al. 2012). Although the most frequent predators are Texas Rat Snakes (Elaphe obsoleta lindheimeri) and fire ants (Solenopsis spp.), avian nest predators are also common and include Western Scrub-jays (Aphelocoma californica) and hawks (Accipiter sp., Buteo sp.), as well as cowbirds (Stake and Cavanagh 2001, Stake and Cimprich 2003, Smith et al. 2004, Conkling et al. 2012). In contrast to other nest predators in central Texas, however, cowbirds often only partially depredate vireo nests, leaving one or more eggs or nestlings in the nest, and do not always cause nest failure (Stake and Cavanaugh 2001, Stake and Cimprich 2003). Like many songbirds, male Black-capped Vireos establish and defend breeding territories through song (Graber 1961, Grzybowski 1995). Song, however, also provides a means of communication between male and female vireos both in pair bonding as well as communication surrounding parental duties (Graber 1961, Grzybowski 1995). Although males and females share nest building and incubation duties, females generally select the nest site, collect the majority of nest material, and spend more time actively building the nest 
and incubating eggs (Graber 1961, Grzybowski 1995). Males generally travel with the female while they collect nesting material and may sing above the nest or nearby while the female is building (Graber 1961, Grzybowski 1995). During incubation, males may also sing when approaching the nest for an incubation switch (Graber 1961, Grzybowski 1995). Thus, male song may provide a cue for nest predators and parasites. Furthermore, vireo populations on and around Fort Hood provide a unique opportunity to investigate vocalization behavior at the nest across a gradient of parasitism risk, as they weigh potential trade-offs with a relatively stable risk of predation.

We assessed the relative benefits (i.e., the trade-offs) presented by vigilance and reticence at the nest for Black-capped Vireos navigating the risks of nest parasitism and predation. We investigated the vocal response of vireos across different nesting stages and times of day and assessed the trade-offs between parasitism and predation risk using two hypotheses: the predatorattraction hypothesis (Aviles et al. 2006, Steckler and Conway 2012) and the parasite-assessment hypothesis (Forsman and Martin 2009, Steckler and Conway 2012). The predatorattraction hypothesis assumes that nest predators use auditory cues to locate nests and that brood parasites use information on perceived predation risk to make decisions about which nests to parasitize (Aviles et al. 2006, Steckler and Conway 2012). This hypothesis predicts that individuals who vocalize frequently near their nests should have a greater probability of incurring nest predation and a lower probability of brood parasitism (Aviles et al. 2006, Steckler and Conway 2012). Because many of the common vireo nest predators are more likely to cue into olfactory signals rather than vocalizations (i.e., nonavian predators, including snakes; Conover 2007), we predicted that support for the predator-attraction hypothesis in this system would be weak. We also expected, however, the impact of parental vocalizations on vireo nest fate might vary throughout the nesting cycle. Nest predation, in general, is not likely to be affected by vocalizations in the building stage but selection to reduce predation pressure may affect vocalization rate in later nesting stages, particularly as the threat cowbirds pose at vireo nests shifts from brood parasite to nest predator (Arcese et al. 1996, Stake and Cavanaugh 2001, Stake and Cimprich 2003, Conkling et al. 2012, Dubina and Peer 2013).

In contrast to the predator-attraction hypothesis, the parasiteassessment hypothesis predicts that nesting individuals perceive parasitism risk based on local parasite densities and that host vocalization rate will be inversely correlated with local parasite density (Forsman and Martin 2009, Steckler and Conway 2012). We expected to find that parasitism risk is a greater influence on vireo nesting behavior than predation risk and that vireos that vocalized more frequently would be more likely to suffer nest parasitism. In particular, we expected that vireos would lower their risk of brood parasitism by being relatively quiet and secretive during the building and laying stages, especially in areas with high cowbird densities. We also hypothesized that vireos breeding in areas where cowbirds are common may make fewer nesting vocalizations in the morning and more in the afternoon or evening relative to vireos breeding in areas with lower parasitism risk.

\section{METHODS}

\section{Study sites}

We chose five study sites in central Texas, on Fort Hood and in nearby areas to the west, that represent a range of cowbird control efforts and offer vireos a range of trade-offs relevant to nest communication (Fig. 1). The habitat within the Hill Country of central Texas is semiarid and largely characterized by shortgrass communities and cattle rangeland. Many ungrazed areas that were once grass or deciduous shrublands are now woodlands due to fire suppression and encroachment by the native evergreen Ashe juniper (Juniperus ashei).

Fig. 1. Study site locations for Black-capped Vireo nest recordings in central Texas, 2013-2014.

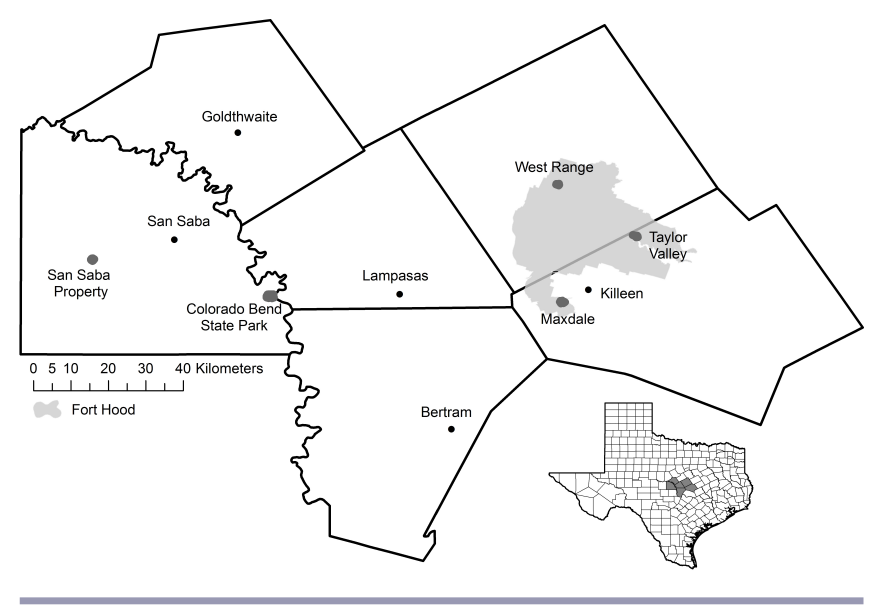

On Fort Hood, we chose three study sites that represented a range of cowbird control: Taylor Valley, West Range, and Maxdale. West Range, dominated by patchy shrublands, mixed juniper, and deciduous woodlands, had comprehensive cowbird control until 2006 when Fort Hood began an experimental cessation of cowbird control in the northwest area of the base. Taylor Valley is located on the eastern side of the installation where cowbirds have been continually controlled via shooting and trapping since 1991. Maxdale is located near the southern edge of the Fort Hood installation and, although cowbirds are removed from the site when they are reported, there are no nearby traps and cowbird presence remains high. A mix of grasslands and deciduous woodlands characterizes both Taylor Valley and Maxdale.

The San Saba study site comprises portions of two neighboring private ranches southwest of San Saba, Texas, nearly $100 \mathrm{~km}$ west of Fort Hood. The site is located on a northwest-facing hillside, dominated by shrublands and deciduous woodlands. Moderate cowbird control efforts began at San Saba in 2014, but cowbirds remained common on the site throughout this study.

Colorado Bend State Park is a 2156.2-ha (5328-acre) state park located almost $60 \mathrm{~km}$ west of Fort Hood, along the west side of the Colorado River in San Saba County, Texas. The study site, along the northeastern boundary of the park, consists of a mix of grassland and patchy juniper and live oak woodlands (Quercus fusiformis). During the course of this study, there was no effective 
cowbird control in the state park except for minimal trapping efforts in 2014.

Although our sites varied in vegetation characteristics, vireo nest behaviors do not differ substantially between habitat types (e.g., attentiveness and visitation rates; Pope et al. 2013). We assumed vegetation patterns would not affect our assessment of vireo behavior and parasitism and predation risk.

\section{Cowbird density estimation}

Cowbird density may be reliably estimated using point counts (Miles and Buehler 2000). Thus, to assess the relative level of cowbird presence, we conducted 10-min, variable distance, point counts across each study site. We based the number of point-count locations roughly on the relative area of each site and spaced count locations at least $200 \mathrm{~m}$ apart (see Appendix 1 for details). At each location, we conducted three rounds of counts in each study year and noted the distance to any cowbirds we detected. Using our observations, we conducted detection-dependent density modeling using the packages "Distance" and "mrds" in R v.3.1.1 (Laake et al. 2014, Miller 2014, R Core Team 2014; see Appendix 1 for details). We evaluated models that varied in key functions, adjustment functions, and data truncation and assumed that cowbird detection did not vary by study site. In total, we compared 19 detection models using AIC (Akaike's Information Criterion; Akaike 1974) and model weights (Appendix 1, Table A1.1). The three top-ranking models of cowbird density had similar levels of support (Table A1.1) but also provided similar estimates of cowbird density. Thus, we relied on the estimates from the top model alone in further analyses.

After evaluating the best model (Table A1.1) for goodness of fit (Kolmogorov-Smirnov $=0.09, P=0.39$ ), we estimated cowbird density on each study site (Table 1). The standard errors for cowbird density estimates were quite large, however, and, at best, these estimates gave us an indication of the relative level of cowbird abundance. Thus, based on our knowledge of cowbird control efforts and our estimates of relative cowbird abundance across our study sites, we classified sites into two categories of relative cowbird density (Table 1). We placed Taylor Valley in the low cowbird density category; the other four sites had high cowbird density (Table 1).

\section{Nest monitoring}

We monitored Black-capped Vireos at each study site in 2013 and 2014. We visited study sites three times a week throughout the breeding season, from late March through mid-July, and searched for territorial males. Upon identifying territories, we visited each territory two or three times a week to identify nesting behavior and locate nests. We visited known nest locations every 3-4 d until the nest either failed or fledged; during each visit, we recorded the number of host eggs and cowbird eggs (if present) and the number and approximate age of nestlings.

\section{Audio recordings}

\section{Nest recordings and site selection}

In central Texas, cowbirds may parasitize vireo nests throughout the breeding season; however, the probability of brood parasitism is relatively low for nests initiated in the first few weeks of April compared with nests initiated in later weeks (Boves et al. 2014).
Thus, to avoid biases in the likelihood of nest parasitism, we recorded vireo vocalizations at nests between sunrise and sunset from mid-April through late June during multiple nest stages: building, egg laying, and early incubation (days 1-4 of incubation). Parasitism events typically occur during the egglaying or early incubation stages, and to avoid unnecessary disruption of the nesting cycle, we did not record vocalizations at nests during later periods of vireo incubation or after eggs hatched. In general, we followed a recording methodology modeled after Clotfelter (1998) and Steckler and Conway (2012). Minimizing disturbance of the nest, we attached a Sennheiser cardioid microphone (Model ME66) to a branch at the approximate height of the nest 3-5 $\mathrm{m}$ away. We angled the microphone between 30 and 45 degrees, pointed back toward the nest to best capture vocalizations at or above the nest. Using a Sony digital voice recorder, we recorded vocalizations for the battery life of the recorder (about $23 \mathrm{~h}$ ). We concealed recorders in vegetation below the microphone. To further help minimize nest disturbance and to avoid drawing the attention of nest predators or parasites due to our recording activities, we made recordings at each nest during only a single nest stage. We avoided recording on days with rain or high wind.

Table 1. Cowbird density (birds $/ \mathrm{km}^{2}$ ), level of cowbird control, and categorical cowbird abundance at Black-capped Vireo breeding sites in central Texas

\begin{tabular}{|c|c|c|c|c|}
\hline \multirow[t]{2}{*}{ Site } & \multicolumn{2}{|c|}{ Cowbird Density } & \multirow{2}{*}{$\begin{array}{l}\text { Level of } \\
\text { Cowbird } \\
\text { Control }\end{array}$} & \multirow{2}{*}{$\begin{array}{l}\text { Categorical } \\
\text { Cowbird } \\
\text { Abundance }\end{array}$} \\
\hline & Estimate & SE & & \\
\hline Colorado Bend & 69.47 & 15.99 & None & High \\
\hline Taylor Valley & 10.19 & 4.97 & Complete & Low \\
\hline San Saba & 57.04 & 20.63 & None & High \\
\hline Maxdale & 89.79 & 18.63 & Moderate & High \\
\hline West Range & 66.55 & 20.82 & None & High \\
\hline
\end{tabular}

We selected nests to record at random within each site. We located most nests we recorded during the building stage $(88 \%, N=46)$ but $12 \%(N=6)$ were located during egg laying. Taylor Valley was the only site with low cowbird density, and we recorded nests at this site in both 2013 and 2014 $(N=17)$. In 2013, we also conducted nest recordings at Maxdale $(N=10)$ and Colorado Bend $(N=11)$ and, in 2014, we recorded nests at West Range $(N=8)$ and San Saba $(N=6)$.

\section{Vocalization rates}

To calculate vocalization rates, we divided each recording into morning (sunrise to 9 am), midday (noon to $3 \mathrm{pm}$ ), and evening ( $6 \mathrm{pm}$ to sunset) time periods and, following the methodology of Steckler and Conway (2012), randomly selected one 30-min section from each time period. We then counted the number of male song vocalizations in each 30 -min section, counting each individual singing bout (bouts separated by $\geq 1$ second) as a single song. Thus, songs could vary in length, but we assume that each singing bout took place from a single location. A single observer with experience observing Black-capped Vireos and their nesting behavior over several breeding seasons (LEW) listened to all recordings and categorized the singer's approximate distance from the nest as "near" or "far" based on the relative volume of 
Table 2. Male Black-capped Vireo vocalization rates (songs/minute) near nests in central Texas, 2013-2014. N is the number of 30-min recordings collected for each nest stage and time of day. Each nest we observed was recorded during a single nest stage and typically provided three 30-min recordings, one during each time period. Standard errors are in parentheses

\begin{tabular}{lcccccccc}
\hline \hline & \multicolumn{9}{c}{ Nest Stage } & & \\
\cline { 2 - 6 } \cline { 3 - 7 } Time of Day & Building & $N$ & Laying & $N$ & Incubation & $N$ & Total \\
\hline Morning & $0.75(0.26)$ & 23 & $0.67(0.19)$ & 18 & $0.65(0.32)$ & 10 & $0.70(0.15)$ \\
MidDay & $1.19(0.19)$ & 23 & $0.27(0.08)$ & 19 & $1.71(0.82)$ & 10 & $0.95(0.19)$ & 51 \\
Evening & $0.27(0.09)$ & 23 & $0.31(0.21)$ & 19 & $0.27(0.15)$ & 10 & $0.28(0.09)$ & 52 \\
Total & $0.73(0.12)$ & 69 & $0.41(0.10)$ & 56 & $0.88(0.31)$ & 30 & $0.64(0.09)$ & 155 \\
\hline
\end{tabular}

vocalizations. To minimize bias in distance categorization, speaker volumes were kept constant (Steckler and Conway 2012). We assumed loud vocalizations were at or above the nest location (near), whereas relatively quiet vocalizations were distant from the nest (far), unlikely to cue a cowbird or predator to the nest location, and, in some cases, may represent a vocalization from a neighboring male. Therefore, we discarded vocalizations determined to be far from the nest, and they were not included in further analyses. Vireo vocalizations other than song were recorded infrequently, and we did not include them in our analyses. For each individual nest, we totaled "near-nest" vocalizations and calculated a vocalization rate (songs/minute) for each 30-min time period. Across nests, we also calculated average vocalization rates (mean $\pm \mathrm{SE}$ songs/minute) for nest stages and time periods. Although male vireos do help incubate (Graber 1961, Grzybowski 1995), the length of each male incubation period is generally short relative to females and is often less than $30 \mathrm{~min}$ (Pope et al. 2013; D. Cimprich, personal communication). Thus, even during the incubation period, we assumed that our methodologies would accurately reflect vireo vocalization frequencies on average.

\section{Analyses}

To test the predator-attraction (Aviles et al. 2006, Steckler and Conway 2012) and parasite-assessment hypotheses (Forsman and Martin 2009, Steckler and Conway 2012), we conducted three analyses of near-nest vocalizations using poisson log-linear models. To assess the predator-attraction hypothesis, we compared models defined a priori considering combinations of nest stage, time of day, and (1) depredation fate (whether the nest was eventually depredated or not) and (2) parasitism fate (whether the nest was eventually parasitized or not). To analyze the parasite-assessment hypothesis, we compared models, considering nest stage, time of day, and (3) estimated cowbird density.

To explain observed vocalizations at vireo nests, we compared seven models in each of three analyses including a null model, a model considering only nest stage, time of day, and their interaction, and additional analysis-specific models that considered either parasitism fate, depredation fate, or cowbird density. We ranked candidate models defined a priori using $\mathrm{AIC}_{\mathrm{c}}$ (AIC adjusted for small sample sizes; Akaike 1974) and assigned a relative probability to each model (Burnham and Anderson 1998). We compared model weights $\left(w_{\mathrm{j}}\right)$, which measure relative support for a particular model within the model set, and considered a model to be competitive if its $\Delta \mathrm{AIC}_{\mathrm{c}}$ was less than 2 (Burnham and Anderson 1998).
After defining our best model for each analysis, we conducted post hoc tests of factor interactions to determine the relationship between nest stage, time of day, and measures of nest fate and cowbird density. All analyses were conducted in R v.3.1.1 (R Core Team 2014); we used the packages "AICcmodavg" (Mazerolle 2015) to calculate $\mathrm{AIC}_{\mathrm{c}}$ (Akaike 1974), and "phia" for all post hoc evaluations (De Rosario-Martinez 2015).

\section{RESULTS}

We recorded vocalizations at 52 nests during the 2013 and 2014 seasons, including 23 nests recorded during building, 19 during laying, and 10 during early incubation (Table 2). We located most nests we recorded during the building stage $(88 \%, N=46)$, but $12 \%(N=6)$ were located during egg laying. Taylor Valley was the only site with low cowbird density, and we recorded nests at this site in both 2013 and 2014 $(N=17)$. In 2013, we also conducted nest recordings at Maxdale $(N=10)$ and Colorado Bend $(N=11)$ and, in 2014, we recorded nests at West Range $(N=8)$ and San Saba $(N=6)$.

Fifteen nests (28.8\%) were eventually parasitized, and $19(36.5 \%)$ were depredated. Four parasitized nests $(26.7 \%)$ were also eventually depredated. On average, males at nests that were eventually parasitized and depredated were more vocal $(N=12$ 30 -min recordings from four nests; $1.13 \pm 0.56$ songs/minute) than nests that were only depredated $(N=45$ recordings from 15 nests; $0.59 \pm 0.17$ songs/minute), only parasitized $(N=33$ recordings from 11 nests; $0.59 \pm 0.14$ songs/minute $)$, or were neither depredated nor parasitized ( $N=65$ recordings from 22 nests; 0.62 \pm 0.12 songs/minute), but this difference was not significant $\left(F_{3,151}=0.84, P=0.47\right)$.

\section{Predator-attraction hypothesis}

\section{Depredation fate}

Nests belonging to vocal males were more likely to be depredated than nests belonging to quiet males in the early incubation stage $\left(\chi^{2}=31.29, P<0.001\right.$; Fig. 2). Conversely, nests were less likely to be depredated when males vocalized more during building $\left(\chi^{2}=\right.$ $51.60, P<0.001)$ and in the laying stage $\left(\chi^{2}=45.72, P<0.001\right.$; Fig. 2). Depredation was also most likely when males vocalized less in the evening $\left(\chi^{2}=54.27, P<0.001\right)$ and more during the middle of the day $\left(\chi^{2}=7.24, P=0.01\right.$; Fig. 2$)$. After comparing seven models relating vocalization rate to combinations of nest stage, time of day, and depredation fate, the best supported model included all main effects and two-way interactions (Tables 3 and 4); there were no other competitive models (Table 3). 
Fig. 2. Predator-attraction hypothesis: depredation fate. Interaction means from the best model of "near-nest" vocalizations by male vireos in central Texas, 20132014, considering depredation fate, (A) time of day and (B) nest stage. Vocalizations at nests that were eventually depredated are indicated in black; vocalizations at nondepredated nests are in gray. Standard errors are all too small to display accurately (all SE are $<0.12$ ).
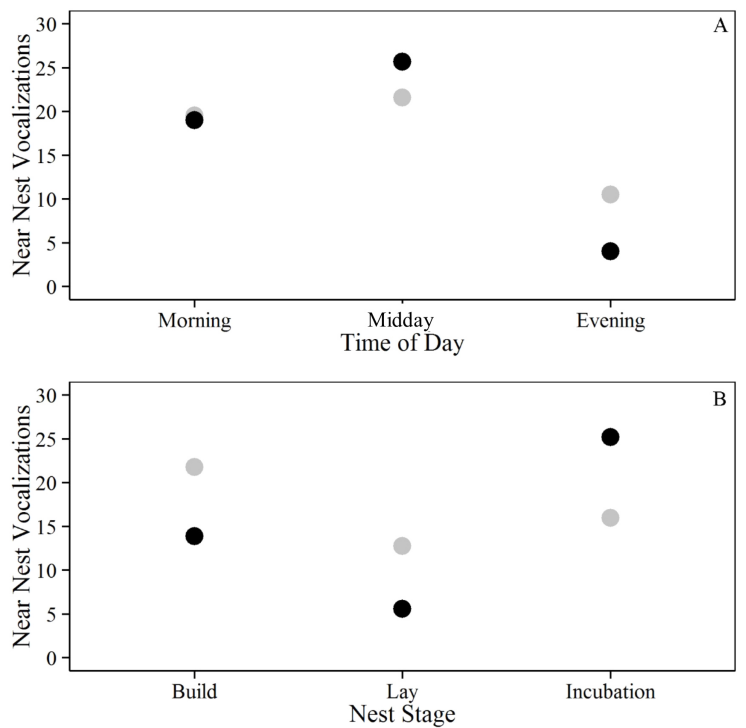

Table 3. Comparison of a priori selected models to assess the predator-attraction hypothesis and the relationship between vocalization rate by male vireos and nest stage (Stage), time of day (Time), and depredation fate (Depr). Models are compared using $\mathrm{AIC}_{\mathrm{c}}$ (Akaike 1974) and model weights (wi)

\begin{tabular}{lcc}
\hline \hline Parameters & $\Delta \mathrm{AIC}_{c}$ & $w_{\mathrm{i}}$ \\
\hline $\begin{array}{l}\text { Stage + Time + Depr + Stage*Time + Stage*Depr }+ \\
\text { Time*Depr }\end{array}$ & $0.00^{\dagger}$ & 1.00 \\
Stage + Time + Depr + Stage*Time + Stage*Depr & 69.23 & $<0.001$ \\
Stage + Time + Depr + Stage*Time + Time*Depr & 126.04 & $<0.001$ \\
Stage + Time + Stage*Time & $223.53<0.001$ \\
Stage + Time + Depr + Stage*Time & $225.80<0.001$ \\
Depr & $1409.56<0.001$ \\
(null) & $1421.39<0.001$ \\
\hline${ }^{\dagger}$ AIC $_{\mathrm{c}}=4934.35$ & &
\end{tabular}

\section{Parasitism fate}

Near nest vocalizations by male vireos were associated with risk of nest parasitism within specific nest stages and periods of the day (Fig. 3). During the laying period, eventual nest parasitism was associated with less frequent vocalizations $\left(\chi^{2}=96.61, P<0.001\right)$, and conversely, in the building and early incubation stages and during the midday, parasitism was positively associated with male vocalizations (building: $x^{2}=29.76, P<0.001$; incubation: $x^{2}=$
144.89, $P<0.001$; midday: $\chi^{2}=8.17, P=0.01$; Fig. 3 ). The best model of vocalization rate considering parasitism fate included all three main effects (nest stage, time of day, and parasitism fate) and all two-way interactions, and no other models were competitive (Tables 5 and 6).

Table 4. Parameter estimates for the best model assessing the predator-attraction hypothesis and the relationship between vocalization rate by male vireos and nest stage (Stage), time of day (Time), and depredation fate (Depr).

\begin{tabular}{lcccc}
\hline \hline$\beta$ & Estimate & SE & $z$ & $P$ \\
\hline Intercept & -0.20 & 0.06 & -3.65 & $<0.001$ \\
Nest Stage (Lay) & -0.10 & 0.08 & -1.30 & 0.20 \\
Nest Stage (Incubation) & -0.57 & 0.10 & -5.86 & $<0.001$ \\
Time of Day (MidDay) & 0.37 & 0.07 & 5.40 & $<0.001$ \\
Time of Day (Evening) & -0.72 & 0.10 & -7.52 & $<0.001$ \\
$\begin{array}{l}\text { Depredation Fate } \\
\text { Nest Stage (Lay)*Time of Day (MidDay) }\end{array}$ & -0.20 & 0.08 & -2.64 & 0.008 \\
$\begin{array}{l}\text { Nest Stage (Incubation)*Time of Day } \\
\text { (MidDay) }\end{array}$ & 0.50 & 0.12 & -11.45 & $<0.001$ \\
Nest Stage (Lay)*Time of Day (Evening) & 0.01 & 0.13 & 0.12 & 0.91 \\
$\begin{array}{l}\text { Nest Stage (Incubation)*Time of Day } \\
\text { (Evening) }\end{array}$ & 0.28 & 0.16 & 1.76 & 0.08 \\
Nest Stage (Lay)*Depredation Fate & -0.38 & 0.13 & -2.88 & 0.004 \\
$\begin{array}{l}\text { Nest Stage (Incubation)*Depredation } \\
\text { Fate }\end{array}$ & 0.91 & 0.09 & 9.96 & $<0.001$ \\
Time of Day (MidDay)*Depredation & 0.20 & 0.09 & 2.27 & 0.02 \\
Fate & & & & \\
Time of Day (Evening)*Depredation & -0.94 & 0.15 & -6.43 & $<0.001$ \\
Fate & & & & \\
\hline
\end{tabular}

Fig. 3. Predator-attraction hypothesis: parasitism fate. Interaction means from the best model of "near-nest" vocalizations by male vireos in central Texas, 2013-2014, considering parasitism fate (A) time of day and (B) nest stage. Vocalizations at nests that were eventually parasitized are indicated in black; vocalizations at nonparasitized nests are in gray. Standard errors are all too small to display accurately (all SE are $<0.13$ ).
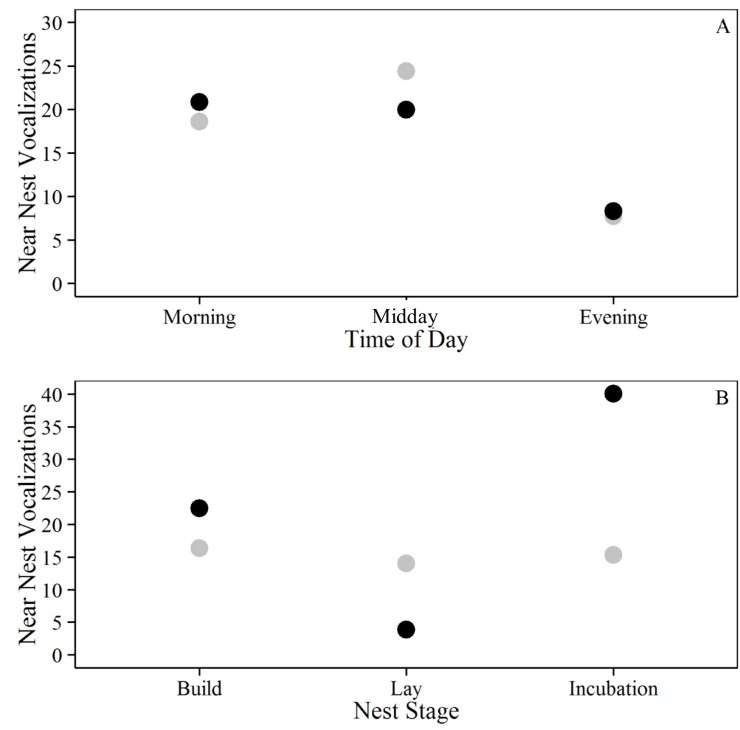


\section{Parasite-assessment hypothesis}

\section{Cowbird density}

Male vireos vocalized more at sites with high cowbird density in general $\left(\chi^{2}=78.20, P<0.001\right)$ and across most individual nest stages (building: $\chi^{2}=150.37, P<0.001$; incubation: $\chi^{2}=101.28, P$ $<0.001$ ) and periods of the day (morning: $\chi^{2}=129.14, P<0.001$; midday: $\chi^{2}=47.97, P<0.001$; evening: $\chi^{2}=4.90, P=0.03$; Fig. 4). During the laying stage, however, male vireos were quieter in areas with relatively high cowbird densities (laying: $\chi^{2}=116.03, P<0.001$; Fig. 4). The best and only competitive model of near-nest vocalizations considering cowbird density included all three main effects (nest stage, time of day, and level of cowbird density) as well as all two-way interactions (Tables 7 and 8).

Table 5. Comparison of a priori selected models to assess the predator-attraction hypothesis and the relationship between vocalization rate by male vireos and nest stage (Stage), time of day (Time), and parasitism fate (Para). Models are compared using $\mathrm{AIC}_{\mathrm{c}}$ (Akaike 1974) and model weights (wi)

\begin{tabular}{lcc}
\hline \hline Parameters & $\Delta \mathrm{AIC}_{\mathrm{c}}$ & $w_{\mathrm{i}}$ \\
\hline Stage + Time + Para + Stage*Time + Stage*Para + & $0.00^{\dagger}$ & 0.99 \\
Time*Para & & \\
Stage + Time + Para + Stage*Time + Stage*Para & 8.54 & 0.01 \\
Stage + Time + Para + Stage*Time & $264.60<0.001$ \\
Stage + Time + Para + Stage*Time + Time*Para & $266.89<0.001$ \\
Stage + Time + Stage*Time & $283.68<0.001$ \\
Para & $1459.86<0.001$ \\
(null) & $1481.54<0.001$ \\
\hline${ }^{\dagger}{ }^{*}{ }^{*}{ }_{c}=4874.20$ & &
\end{tabular}

Table 6. Parameter estimates for the best model assessing the predator-attraction hypothesis and the relationship between vocalization rate by male vireos and nest stage (Stage), time of day (Time), and parasitism fate (Para)

\begin{tabular}{lcccc}
\hline \hline$\beta$ & Estimate & SE & $z$ & $P$ \\
\hline Intercept & -0.47 & 0.06 & -8.32 & $<0.001$ \\
Nest Stage (Lay) & 0.28 & 0.08 & 3.60 & $<0.001$ \\
Nest Stage (Incubation) & -0.29 & 0.09 & -3.15 & 0.002 \\
Time of Day (Midday) & 0.59 & 0.07 & 8.71 & $<0.001$ \\
Time of Day (Evening) & -1.00 & 0.10 & -9.66 & $<0.001$ \\
Parasitism Fate & 0.44 & 0.08 & 5.68 & $<0.001$ \\
Nest Stage (Lay)*Time of Day (Midday) & -1.50 & 0.12 & -12.90 & $<0.001$ \\
Nest Stage (Incubation)*Time of Day & 0.53 & 0.10 & 5.27 & $<0.001$ \\
(Midday) & & & & \\
Nest Stage (Lay)*Time of Day (Evening) & 0.21 & 0.13 & 1.60 & 0.11 \\
Nest Stage (Incubation)*Time of Day & 0.15 & 0.16 & 0.96 & 0.34 \\
(Evening) & & & & \\
Nest Stage (Lay)*Parasitism Fate & -1.61 & 0.14 & -11.26 & $<0.001$ \\
Nest Stage (Incubation)*Parasitism Fate & 0.64 & 0.09 & 7.09 & $<0.001$ \\
Time of Day (Midday)*Parasitism Fate & -0.32 & 0.09 & -3.46 & 0.001 \\
Time of Day (Evening)*Parasitism Fate & -0.04 & 0.13 & -0.31 & 0.76 \\
\hline
\end{tabular}

Fig. 4. Parasite-assessment hypothesis: local cowbird density. Interaction means from the best model of "near-nest" vocalizations by male vireos in central Texas, 2013-2014, considering cowbird density and (A) time of day and (B) nest stage. Vocalizations in areas with high cowbird density are indicated in black, low cowbird density in gray. Standard errors are all too small to display accurately (all SE are <0.22).
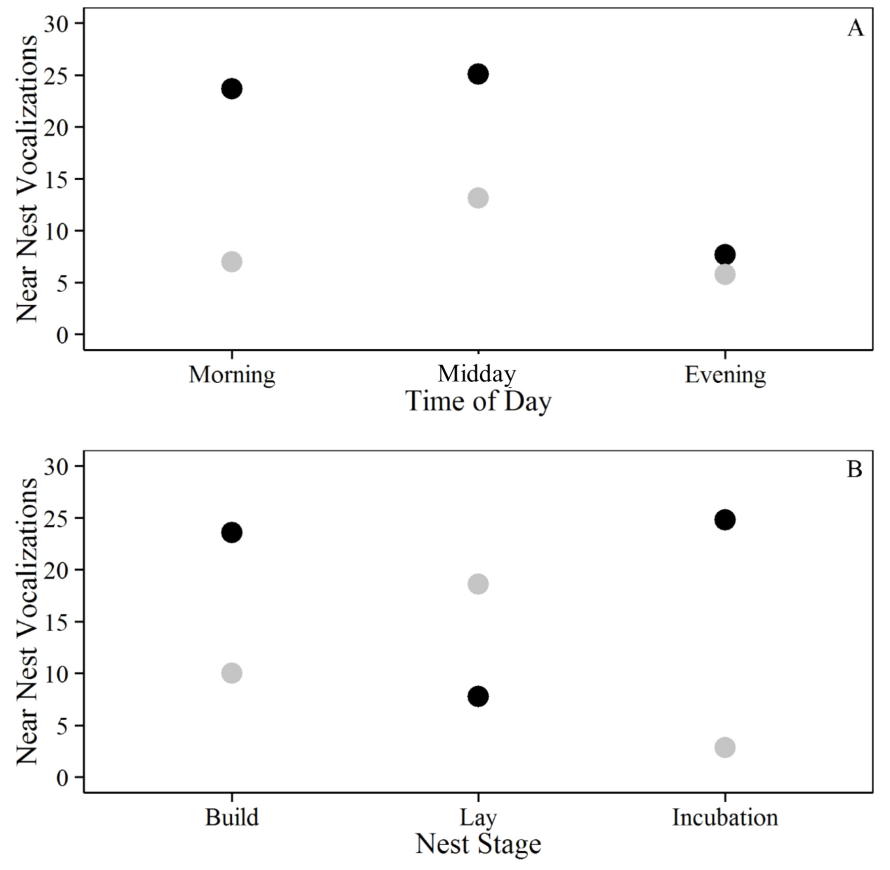

Table 7. Comparison of a priori selected models to assess the parasite-assessment hypothesis and the relationship between vocalization rate by male vireos and nest stage (Stage), time of day (Time), and local cowbird density (Cowbird). Models are compared using $\mathrm{AIC}_{\mathrm{c}}$ (Akaike 1974) and model weights (wi)

\begin{tabular}{lcc}
\hline \hline Parameters & $\Delta \mathrm{AIC}_{c}$ & $w_{\mathrm{j}}$ \\
\hline $\begin{array}{l}\text { Stage + Time + Cowbird + Stage*Time + Stage* } \\
\text { Cowbird + Time*Cowbird }\end{array}$ & $0.00^{\dagger}$ & 1.000 \\
Stage + Time + Cowbird + Stage*Time + Stage* & & \\
Cowbird & 48.79 & $<0.001$ \\
Stage + Time + Cowbird + Stage*Time + Time*Cowbird & $373.41<0.001$ \\
Stage + Time + Cowbird + Stage*Time & $438.18<0.001$ \\
Stage + Time + Stage*Time & $591.25<0.001$ \\
Cowbird & $1631.13<0.001$ \\
(null) & $1789.10<0.001$ \\
\hline${ }^{\dagger} \mathrm{AIC}_{\mathrm{c}}=4566.63$ & & \\
\end{tabular}


Table 8. Parameter estimates for the best model assessing the parasite-assessment hypothesis and the relationship between vocalization rate by male vireos and nest stage (Stage), time of day (Time), and local cowbird density (Cowbird)

\begin{tabular}{lcccc}
\hline \hline$\beta$ & Estimate & SE & $z$ & $P$ \\
\hline Intercept & 0.05 & 0.05 & 1.12 & 0.26 \\
Nest Stage (Lay) & -0.57 & 0.08 & -7.58 & $<0.001$ \\
Nest Stage (Incubation) & -0.28 & 0.09 & -3.25 & 0.001 \\
Time of Day (Midday) & 0.36 & 0.06 & 6.01 & $<0.001$ \\
Time of Day (Evening) & -1.22 & 0.09 & -13.15 & $<0.001$ \\
Cowbird Density (Low) & -1.36 & 0.10 & -13.33 & $<0.001$ \\
Nest Stage (Lay)*Time of Day (Midday) & -1.56 & 0.12 & -13.16 & $<0.001$ \\
Nest Stage (Incubation)*Time of Day & 0.66 & 0.10 & 6.37 & $<0.001$ \\
(Midday) & & & & \\
Nest Stage (Lay)*Time of Day (Evening) & -0.06 & 0.13 & -0.45 & 0.65 \\
Nest Stage (Incubation)*Time of Day & 0.33 & 0.16 & 2.03 & 0.04 \\
(Evening) & & & & \\
Nest Stage (Lay)*Cowbird Density (Low) & 1.73 & 0.11 & 16.03 & $<0.001$ \\
Nest Stage (Incubation)*Cowbird & -1.31 & 0.22 & -5.91 & $<0.001$ \\
Density (Low) & & & & \\
Time of Day (Midday)*Cowbird Density & 0.58 & 0.12 & 4.97 & $<0.001$ \\
(Low) & & & & \\
Time of Day (Evening)*Cowbird Density & 0.94 & 0.14 & 6.85 & $<0.001$ \\
(Low) & & & & \\
\hline
\end{tabular}

\section{Importance of nest stage and time of day}

Nest stage, time of day, and their interaction were important in all analyses described above and better explained patterns in vireo vocalizations than either depredation fate, parasitism fate, or cowbird density alone (Tables 3, 5, and 7). In the midday, male song rate at nests was greatest in the incubation and building stages and relatively low during laying (Table 2). During building and incubation, vocalization rates were lowest in the evening and highest in the midday. Song rates in the morning were moderate but significantly greater than in the evening and less than at midday. During the laying stage, near-nest vocalizations were most frequent in the morning. These vocalization patterns in response to nest stage and time of day were consistent across all final models that tested the predator-attraction and parasite-assessment hypotheses (although $\chi^{2}$ values varied between analyses, all $P<0.001$ ).

\section{DISCUSSION}

Vocalizations near nests are known to attract predators and brood parasites for some host species (Uyehara and Narins 1995, Clotfelter 1998, Banks and Martin 2001) and reduce rates of parasitism for others (Sharp and Kus 2006, Steckler and Conway 2012). For the endangered Black-capped Vireo, we found only limited, stage-specific evidence for both the predator-attraction and parasite-assessment hypotheses across landscapes that vary in parasitism risk. Thus, we suggest that neither hypothesis adequately captures the selection pressures that shape vireo vocalization patterns. Black-capped Vireos face a cruel bind in navigating the risks of predation and brood parasitism, a bind that they solve, in part, through temporal plasticity in vocalization frequency near the nest.

\section{Predator-attraction hypothesis}

Patterns in Black-capped Vireo vocalizations near their nests do not support the predictions outlined by the predator-attraction hypothesis. Across all recordings, the relationships observed between song rate and depredation and parasitism fate were in contrast to the expectations of this hypothesis; namely, nests with more vocal males were less likely to be depredated, and there was no relationship between parasitism and song rate. Additionally, although we found some temporal variation between vireo defense strategies, patterns relating vocalization frequency and depredation or parasitism fate were generally consistent, suggesting that vireos experience minimal trade-offs in mediating parasitism or predation risk through vocalizations.

We suspect that, during the early stages of the nesting cycle, selection for an optimal frequency of vocalizations at the nest might focus most on minimizing the threat of cowbird parasitism. Although the predator-attraction hypothesis assumes that important nest predators cue in to parental behaviors such as vocalizations, this may not be true for vireos, particularly during the early nesting stages. Vireos' most common nest predatorssnakes and ants (Stake and Cavanagh 2001, Stake and Cimprich 2003, Conkling et al. 2012) _ are not known to respond to aural cues such as vocalizations (Conover 2007). Additionally, although many of the vireo's avian predators do likely cue into vocalizations (e.g., Western Scrub-jays; Curry et al. 2002), predation events by birds other than cowbirds are relatively uncommon (Stake and Cimprich 2003). Cowbirds are most likely to depredate nests that are located late in the nesting cycle (Conkling et al. 2012), in some cases forcing the host pair to renest and giving the cowbird another parasitism opportunity (Arcese et al. 1996, Stake and Cavanaugh 2001, Dubina and Peer 2013). Thus, had we observed vocalization behavior at vireo nests during nestling development, we might have garnered more support for the predator-attraction hypothesis.

\section{Parasite-assessment hypothesis}

In central Texas, the frequency of Black-capped Vireo vocalizations is strongly correlated with local cowbird density, although generally not in the direction predicted by the parasiteassessment hypothesis. During the building and incubation stages, vireo vocalizations near the nest were most frequent at sites with higher cowbird densities. Thus, although cowbirds may be attracted to singing vireos, it does not appear that vireos adjust song to counter this threat. During the laying stage, however, vocalization rates were highest in areas where cowbird density is low, perhaps providing some stage-specific evidence for the parasite-assessment hypothesis. Cowbirds typically parasitize nests near the end of the laying stage (Davies 2000), and vireos may vocalize less frequently in response to increases in perceived parasitism risk during this nest stage (Forsman and Martin 2009). Alternatively, high cowbird densities may induce nest vigilance by vireos during the building or early incubation stages, although the mechanism for this phenomenon is not obvious.

\section{Reticence vs. vigilance, alternative strategies for nest success}

Although we observed little evidence of trade-offs between the mediation of risk for predators and brood parasites, some stagespecific patterns provide clues as to how vireos balance the risks and benefits of social communication. Temporally specific behavioral adaptations by vireos may alleviate some conflicts in nest defense strategy and ultimately optimize nest success. Cowbirds often locate nests while hosts are building and then 
return to parasitize the nest during the host laying period (Davies 2000, Banks and Martin 2001). Vireos may minimize their risk of eventual nest parasitism by remaining quiet during the building stage to prevent cowbirds from finding the nest location. Nests that are discovered by cowbirds may be abandoned before laying occurs because vireos are less invested in the particular nest location. Once laying begins, however, vireos are more invested in their nest and benefit by remaining vigilant to ward off potential brood parasites. Previous studies found that vireo nests suffer higher rates of predation during the nestling stage compared with incubation (Stake and Cimprich 2003, Conkling et al. 2012), but these studies did not evaluate predation rates during laying or early incubation periods. We assumed that nest predation rates would be highest during times of peak predator activity and, in general, avian predators of vireo nests on Fort Hood, including cowbirds, act diurnally (Stake and Cimprich 2003). Stake and Cavanagh (2001) observed that cowbirds depredating vireo nests during the nestling stage most frequently acted during the midday between 10:00 and 15:00 h. Scrub-jays and other corvids are generally active throughout the day, although the specific timing of predation events is unreported (Luginbuhl et al. 2001, Eggers et al. 2005). Thus, vireos may minimize depredation threat by being relatively quiet during the middle of the day when avian predators are most active.

Although patterns demonstrate that, in general, parasitism and predation risks do not require conflicting defense strategies during the early nesting stages, some differences in risk mediation suggest that, in cases of conflict, vireos minimize loss by optimizing behavior to defend against nest predation. During the building stage, for example, vigilant and more vocal vireos reduced their susceptibility to eventual nest depredation while increasing their risk of parasitism, even in the face of high cowbird densities. In the evenings, vireos that remained vigilant did not increase their risk of nest parasitism but were able to reduce their probability of nest depredation.

Although vireos demonstrate some flexibility in the timing of vocalizations, selection pressures for pair bonding and territory defense may limit plasticity in social communication. In areas with high cowbird densities, vireos became more vigilant during the building stage, when cowbirds typically locate nests (Banks and Martin 2001), and more secretive when they were laying, when brood parasitism generally occurs (Davies 2000). These were not, however, effective defense strategies against parasitism; birds that vocalized more during building and less during the laying stage were also more often parasitized. Additionally, these patterns may amplify one another; if cowbirds are able to follow aural cues and locate a nest during the building stage (Davies 2000, Banks and Martin 2001), vireo reticence during laying may inadvertently aid cowbirds by allowing them more uninterrupted access to the nest. Although vigilance during building may reflect a trade-off with predation risk, we did not observe evidence for such a trade-off during the laying stage. During laying, frequent vocalizations near the nest increased the likelihood of both parasitism and depredation. Instead, vireo territory density and trade-offs with territory defense may help explain these apparent conflicts. High host density may favor selection for territory defense and increased vocalization rates. Indeed, previous studies have positively correlated vireo densities with parasitism rates (Barber and Martin 1997). Thus, at sites with high cowbird densities, vocalization rates may reflect selection for territory defense rather than parasitism risk. Alternatively, at high cowbird densities, building vireos may be more likely to become incidentally discovered by a cowbird, regardless of vocalization rate. Under those circumstances, mate communication may outweigh reticence as an effective defense against parasitism. In general, the apparent limits in Black-capped Vireo vocalization flexibility may in part explain why cowbird parasitism is so detrimental to this species and, without adaptation, vireo populations may remain reliant on intensive management programs that include cowbird control.

In contrast to our results, nest parasitism in a similar species, Bell's vireo, was negatively correlated with vigilance and increased vocalization near the nest during the building and incubation stages but not during laying (Steckler and Conway 2012). Bell's vireo vocalizations during laying were positively correlated with eventual parasitism, although the difference was not significant. This contrast between two very similar species may suggest that, in some cases, parasitism is affected by behaviors not captured well by audio recordings, for example, early initiation of egg laying (Boves et al. 2014) or female presence on the nest (Neudorf and Sealy 1994). Alternatively, trade-offs between behavior and predation risk may differ across habitat types and predator guilds (e.g., Kotler et al. 1991, Heithaus et al. 2008, Cresswell and Quinn 2013), resulting in different vocalization patterns in response to risk of brood parasitism.

Vocalization behavior and parasitism risk have an interactive relationship that is made increasing complex by the additional consideration of nest predation. Although, in many species, more vocal individuals suffer higher rates of brood parasitism (Uyehara and Narins 1995, Clotfelter 1998, Banks and Martin 2001), adaptation of vocalization behaviors that minimize parasitism risk may be outweighed by selection for behaviors that enable individuals to maintain important conspecific bonds or minimize risk of nest predation. Species that do not have nest predators cued by auditory signals, however, may be able to more readily adapt vocalization patterns that minimize parasitism risk. Without the complications of additional trade-offs with predation, some species may develop more temporal flexibility and avoid vocalizing during periods of the day or stages of the nesting cycle when they are most vulnerable to brood parasitism.

Responses to this article can be read online at: http://www.ace-eco.org/issues/responses.php/923

\section{Acknowledgments:}

We thank all of our numerous field technicians for their hard work and dedication, without which this project would not have been possible. Additionally, we thank the private landowners, Texas State Parks and Wildlife staff at Colorado Bend State Park, and the staff of the Natural Resources Division at Fort Hood for enabling and facilitating this research. This work was funded by the Strategic Environmental Research and Development Program (SERDP) as part of project $R C-2120$. This work was approved and permitted by the U.S. Fish and Wildlife Service (Federal Fish and Wildlife Permit TE023643, Special Use Application and Permit 75678), the U.S. 
Geological Survey (Federal Bird Banding Permit 21999), the Texas Parks and Wildlife Department (Scientific Research Permit No. SPR-0409-079), and by the University of Washington IACUC protocol 3077-01.

\section{LITERATURE CITED}

Akaike, H. 1974. A new look at the statistical model identification. Institute of Electrical and Electronics Engineers Transactions on Automatic Control 19:716-723. http://dx.doi.org/10.1109/ TAC.1974.1100705

Arcese, P., J. N. M. Smith, and M. I. Hatch. 1996. Nest predation by cowbirds and its consequences for passerine demography. Proceedings of the National Academy of Sciences 93:4608-4611. http://dx.doi.org/10.1073/pnas.93.10.4608

Aviles, J. M., B. G. Stokke, and D. Parejo. 2006. Relationship between nest predation suffered by hosts and Brown-headed Cowbird parasitism: a comparative study. Evolutionary Ecology 20:97-111. http://dx.doi.org/10.1007/s10682-005-4989-7

Banks, A. J., and T. E. Martin. 2001. Host activity and the risk of nest parasitism by Brown-headed Cowbirds. Behavioral Ecology 12:31-40. http://dx.doi.org/10.1093/oxfordjournals. beheco.a000375

Barber, D. R., and T. E. Martin. 1997. Influence of alternate host densities on Brown-headed Cowbird parasitism rates in Blackcapped Vireos. Condor 99:595-604. http://dx.doi.org/10.2307/1370472

Barclay, R. M. R., M. L. Leonard, and G. Friesen. 1985. Nocturnal singing by Marsh Wrens. Condor 87:418-422. http:// dx.doi.org/10.2307/1367225

Boves, T. J., J. H. Sperry, K. Comolli, and P. J. Weatherhead. 2014. Brood parasitism of Black-capped Vireos: frontline and postlaying behavioral responses and effects on productivity. Journal of Field Ornithology 85:364-378. http://dx.doi.org/10.1111/ jofo. 12076

Bradbury, J. W., and S. L. Vehrencamp. 2011. Principles of animal communication. Second edition. Sinauer Associates, Sunderland, Massachusetts, USA.

Burnham, K. P., and D. R. Anderson. 1998. Model selection and inference: a practical information theoretic approach. SpringerVerlag, New York, New York, USA. http://dx.doi. org/10.1007/978-1-4757-2917-7

Catchpole, C. K. 1987. Bird song, sexual selection and female choice. Trends in Ecology and Evolution 2:94-97. http://dx.doi. org/10.1016/0169-5347(87)90165-0

Cimprich, D. A., and P. M. Cimprich. 2015. Monitoring of the Black-capped Vireo (Vireo atricapilla) during 2014 on Fort Hood Military Installation, Fort Hood, Texas. Pages 6-27 in U.S. Fish and Wildlife Service. 2015 United States Fish and Wildlife Service Annual Report: Endangered Species Monitoring and Management on Fort Hood Military Installation, Fort Hood, Texas. Directorate of Public Works, Natural and Cultural Resources Management Branch, Fort Hood, Texas, USA.

Clotfelter, E. D. 1998. What cues do Brown-headed Cowbirds use to locate Red-winged Blackbird host nests? Animal Behaviour 55:1181-1189. http://dx.doi.org/https://doi.org/10.1006/anbe.1997.0638
Conkling, T. J., T. L. Pope, K. N. Smith, H. A. Mathewson, M. L. Morrison, R. N. Wilkins, and J. W. Cain, III. 2012. Blackcapped Vireo nest predator assemblage and predictors for nest predation. Journal of Wildlife Management 76:1401-1411. http:// dx.doi.org/10.1002/jwmg.388

Conover, M. R. 2007. Predator-prey dynamics: the use of olfaction. Taylor and Francis, Boca Raton, Florida, USA. http:// dx.doi.org/10.1201/9781420009125

Cornell, H. N., J. M. Marzluff, and S. Pecoraro. 2012. Social learning spreads knowledge about dangerous humans among American Crows. Proceedings of the Royal Society B 279:499508. http://dx.doi.org/10.1098/rspb.2011.0957

Cresswell, W., and J. L. Quinn. 2013. Contrasting risks from different predators change the overall nonlethal effects of predation risk. Behavioral Ecology 24:871-876. http://dx.doi. org/10.1093/beheco/art023

Curry, R. L., A. T. Peterson, and T. A. Langen. 2002. Western Scrub Jay (Aphelocoma californica). Account 712 in A. Poole, editor. The Birds of North America Online. Cornell Lab of Ornithology, Ithaca, New York, USA. [online] URL: http://bna. birds.cornell.edu/bna/species/712 http://dx.doi.org/10.2173/bna.712

Davies, N.B. 2000. Cuckoos, cowbirds and other cheats. T. and A. D. Poyser Ltd., London, UK.

De Rosario-Martinez, H. 2015. Phia: post-hoc interaction analysis. R package version 0.2-0. [online] URL: http://CRAN. $\mathrm{R}$-project.org/package $=$ phia.

Dubina, K. M., and B. D. Peer. 2013. Egg pecking and discrimination by female and male Brown-headed Cowbirds. Journal of Ornithology 154:553-557. http://dx.doi.org/10.1007/ s10336-012-0916-1

Eggers, S., M. Griesser, and J. Ekman. 2005. Predator-induced plasticity in nest visitation rates in the Siberian Jay (Perisoreus infaustus). Behavioral Ecology 16:309-315. http://dx.doi. org/10.1093/beheco/arh163

Ficken, R. W., M. S. Ficken, and J. P. Hailman. 1974. Temporal pattern shifts to avoid acoustic interference in singing birds. Science 183:762-763. http://dx.doi.org/10.1126/science.183.4126.762

Forsman, J. T., and T. E. Martin. 2009. Habitat selection for parasite-free space by hosts of parasitic cowbirds. Oikos 118:464 470. http://dx.doi.org/10.1111/j.1600-0706.2008.17000.x

Fuller, R. A, P. H. Warren, and K. J. Gaston. 2007. Daytime noise predicts nocturnal singing in urban robins. Biology Letters 3:368370. http://dx.doi.org/10.1098/rsbl.2007.0134

Ghalambor, C. K., and T. E. Martin. 2000. Parental investment strategies in two species of nuthatch vary with stage-specific predation risk and reproductive effort. Animal Behaviour 60:263267. http://dx.doi.org/10.1006/anbe.2000.1472

Graber, J. W. 1961. Distribution, habitat requirements and life history of the Black-capped Vireo (Vireo atricapilla). Ecological Monographs 31:313-336. http://dx.doi.org/10.2307/1950756

Grzybowski, J. A. 1995. Black-capped Vireo (Vireo atricapilla). Number 181 in The Birds of North America. U.S. Geological Survey, Washington, D.C., USA. http://dx.doi.org/10.2173/ bna. 181 
Haff, T. M., and R. D. Magrath. 2011. Call at a cost: elevated nestling calling attracts predators to active nests. Biology Letters 7:493-495. http://dx.doi.org/10.1098/rsbl.2010.1125

Heithaus, M. R., A. Frid, A. J. Wirsing, and B. Worm. 2008. Predicting ecological consequences of marine top predator declines. Trends in Ecology and Evolution 23:202-210. http://dx. doi.org/10.1016/j.tree.2008.01.003

Kostecke, R. M., S. G. Summers, G. H. Eckrich, and D. A. Cimprich. 2005. Effects of Brown-headed Cowbird (Molothrus ater) removal on Black-capped Vireo (Vireo atricapilla) nest success and population growth at Fort Hood, Texas. Ornithological Monographs 57:28-37. http://dx.doi.org/10.2307/40166812

Kotler, B. P., J. S. Brown, and O. Hasson. 1991. Factors affecting gerbil foraging behavior and rates of owl predation. Ecology 72:2249-2260. http://dx.doi.org/10.2307/1941575

Kroodsma, D. E., and B. E. Byers. 1991. The function(s) of bird song. American Zoologist 31:318-328. http://dx.doi.org/10.1093/ $\mathrm{icb} / 31.2 .318$

Laake, J., D. Borchers, L. Thomas, D. Miller, and J. Bishop. 2014. Mrds: mark-recapture distance sampling ( $m r d s)$. $\mathrm{R}$ package version 2.1.10. [online] URL: http://CRAN.R-project.org/ package $=$ mrds

Lima, S. L. 2009. Predators and the breeding bird: behavioural and reproductive flexibility under the risk of predation. Biological Reviews Cambridge Philosophical Society 84:485-513. http://dx. doi.org/10.1111/j.1469-185X.2009.00085.X

Lougheed S. C., and P. Handford. 1989. Night songs of the Rufous-collared Sparrow. Condor 91:462-465. http://dx.doi. org/10.2307/1368324

Luginbuhl, J. M., J. M. Marzluff, J. E. Bradley, M. G. Raphael, and D. E. Varland. 2001. Corvid techniques and the relationship between corvid relative abundance and nest predation. Journal of Field Ornithology 72:556-572. http://dx.doi.org/10.1648/0273-8570-72.4.556

Marzluff, J. M., and R. P. Balda. 1992. The Pinyon Jay, behavioural ecology of a colonial and cooperative corvid. T. and A. D. Poyser Ltd., London, UK.

Mazerolle, M. J. 2015. AICcmodavg: model selection and multimodel inference based on (Q) AICC. R package version 2.0-3. [online] URL: http://CRAN.R-project.org/package=AICcmodavg

McDonald, P. G., D. R. Wilson, and C. S. Evans. 2009. Nestling begging increases predation risk, regardless of spectral characteristics or avian mobbing. Behavioral Ecology 20:821-829. http://dx.doi.org/10.1093/beheco/arp066

McLean, I. G., J. N. M. Smith, and K. G. Stewart. 1986. Mobbing behaviour, nest exposure, and breeding success in the American Robin. Behaviour 96:171-185. http://dx.doi.org/10.1163/156853986X00270

Miles, R. K., and D. A. Buehler. 2000. An evaluation of point counts and playbacks as techniques for censusing Brown-headed Cowbirds. Pages 63-68 in J. N. M. Smith, T. L. Cook, S. I. Rothstein, and S. G. Sealy, editors. Ecology and management of cowbirds and their hosts: studies in the conservation of North
American passserine birds. University of Texas Press, Austin, Texas, USA.

Miller, D. L. 2014. Distance: a simple way to fit detection functions to distance sampling data and calculate abundanceldensity for biological populations. $\mathrm{R}$ package version 0.9.2. [online] URL: http://CRAN.R-project.org/package=Distance.

Neudorf, D. L., and S. G. Sealy. 1994. Sunrise nest attentiveness in cowbird hosts. Condor 96:162-169. http://dx.doi.org/10.2307/1369073

Nowicki, S., and W. A. Searcy. 2005. Song and mate choice in birds: how the development of behavior helps us understand function. Auk 122:1-14. http://dx.doi.org/10.1642/0004-8038 (2005)122[0001:SAMCIB]2.0.CO;2

Payne, R. B. 1977. The ecology of brood parasitism in birds. Annual Review of Ecological Systems 8:1-28. http://dx.doi. org/10.1146/annurev.es.08.110177.000245

Pope, T. L., T. J. Conkling, K. N. Smith, M. R. Colon, M. L. Morrison, and R. N. Wilkins. 2013. Effects of adult behavior and nest-site characteristics on Black-capped Vireo nest survival. Condor 115:155-162. http://dx.doi.org/10.1525/cond.2012.110141

R Core Team. 2014. R: a language and environment for statistical computing. R Foundation for Statistical Computing, Vienna, Austria. [online] URL: http://www.R-project.org/

Ratzlaff, A. 1987. Endangered and threatened wildlife and plants: determination of the Black-capped Vireo to be an endangered species. Federal Register 52:37420-37423.

Rothstein, S. I. 1975. Evolutionary rates and host defenses against avian brood parasitism. American Naturalist 109:161-176. http:// dx.doi.org/10.1086/282984

Scott, D. M. 1991. The time of day of egg laying by the Brownheaded Cowbird and other icterines. Canadian Journal of Zoology 69:2093-2099. http://dx.doi.org/10.1139/z91-292

Sharp, B. L., and B. E. Kus. 2006. Factors influencing the incidence of parasitism of Least Bell's Vireos. Journal of Wildlife Management 70:682-690. http://dx.doi.org/10.2193/0022-541X (2006)70[682:FITIOC]2.0.CO;2

Skutch, A. F. 1976. Parent birds and their young. University of Texas Press, Austin, Texas, USA.

Smith, J. E., S. J. Taylor, C. J. Whelan, M. L. Denight, and M. M. Stake. 2004. Behavioral interactions between fire ants and vertebrate nest predators at two Black-capped Vireo nests. Wilson Bulletin 116:163-166. http://dx.doi.org/10.1676/0043-5643(2004) 116[0163:BIBFAA]2.0.CO;2

Stake, M. M., and P. M. Cavanagh. 2001. Removal of host nestlings and fecal sacs by Brown-headed Cowbirds. Wilson Bulletin 113:456-459. http://dx.doi.org/10.1676/0043-5643(2001) 113[0456:ROHNAF]2.0.CO;2

Stake, M. M., and D. A. Cimprich. 2003. Using video to monitor predation at Black-capped Vireo nests. Condor 105:348-357. http://dx.doi.org/10.1650/0010-5422(2003)105[0348:UVTMPA]2.0. $\mathrm{CO} ; 2$

Steckler, S. E., and C. J. Conway. 2012. Frequent vocalizing is negatively associated with brood parasitism in a host of the 
Brown-headed Cowbird. Condor 114:219-226. http://dx.doi. org/10.1525/cond.2012.110006

Trivers, R. I. 1972. Parental investment and sexual selection. Pages 52-95 in B. Campbell, editor. Sexual selection and the descent of man. 1871-1971. Skyline Publishing, Chicago, Illinois, USA.

Uyehara, J. C., and P. M. Narins. 1995. Nest defense by Willow Flycatchers to brood-parasitic intruders. Condor 97:361-368. http://dx.doi.org/10.2307/1369022

Walker, L. E. 2015. Population dynamics of the endangered Blackcapped Vireo (Vireo atricapilla). Dissertation, University of Washington, Seattle, Washington, USA.

Warren, P. S., M. Katti, M. Ermann, and A. Brazel. 2006. Urban bioacoustics: it's not just noise. Animal Behaviour 71:491-502. http://dx.doi.org/10.1016/j.anbehav.2005.07.014 
Appendix 1. To assess the level of Brown-headed Cowbird (cowbird; Molothrus ater) presence on each of five Black-capped Vireo (vireo; Vireo atricapilla) breeding sites, we conducted variable distance point-counts. We based the number of point-count locations roughly on the relative area of each site and conducted counts at seven locations on Taylor Valley, nine on Maxdale, five on West Range, five on San Saba, and 13 on Colorado Bend. Point-count locations were at least $200 \mathrm{~m}$ apart. At each location, we conducted three rounds of 10-minute counts in 2013 and three in 2014, noting the distance to any cowbirds we detected. Using our point-count observations, we conducted detection-dependent density modelling using the packages "Distance" and "mrds" in R v.3.1.1 (Laake et al. 2014, Miller 2014, R Core Team 2014). We compared detection models with half-normal or hazard-rate key functions, cosine or simple polynomial adjustment functions with an optimized number of adjustment terms, and variations in data truncation using Akaike's Information Criterion (AIC; Akaike 1974, Table A1.1). We compared models with no truncation of the data, left truncation only, right truncation only, and both right and left data truncation. In several cases, adjustment functions did not improve the model and, in total, we compared 19 models using AIC (Akaike's Information Criterion; Akaike 1974) and model weights (Table A1.1). The best detection model estimated cowbird density using the hazard rate key function, no adjustment terms, and both left and right truncation of the data (Table A1.1). 
Table A1.1. Detection models used to evaluate cowbird density at five Black-capped Vireo breeding sites, comparing half-normal or hazard-rate key functions, cosine or simple polynomial adjustment functions, and variations in data truncation (truncation distances are in $\mathrm{km})$.

\begin{tabular}{|c|c|c|c|}
\hline Cowbird Detection Model & $\mathrm{AIC}$ & $\Delta \mathrm{AIC}$ & $w_{\mathrm{i}}$ \\
\hline Hazard-Rate, No adjustments, Left Truncation at 0.01 , Right Truncation at 0.091 & -558.64 & 0.00 & 0.37 \\
\hline Hazard-Rate, No adjustments, Left Truncation at 0.01 , Right Truncation at 0.097 & -558.39 & 0.25 & 0.32 \\
\hline Hazard-Rate, No adjustments, Left Truncation at 0.01, Right Truncation at 0.087 & -557.80 & 0.83 & 0.24 \\
\hline Half-Normal, Cosine (2) adjustments, Left Truncation at 0.01, Right Truncation at & -552.60 & 6.04 & 0.02 \\
\hline Half-Normal, No adjustments, Left Truncation at 0.01, Right Truncation at 0.087 & -552.24 & 6.40 & 0.02 \\
\hline Half-Normal, No adjustments, Left Truncation at 0.01 , Right Truncation at 0.091 & -551.97 & 6.67 & 0.01 \\
\hline Half-Normal, No adjustments, Left Truncation at 0.01 , Right Truncation at 0.091 & -551.97 & 6.67 & 0.01 \\
\hline Hazard-Rate, No adjustments, No Left Truncation, Right Truncation at 0.091 & -550.00 & 8.64 & 0.005 \\
\hline Half-Normal, No adjustments, Left Truncation at 0.01 , Right Truncation at 0.097 & -549.92 & 8.72 & 0.005 \\
\hline Hazard-Rate, No adjustments, No Left Truncation, Right Truncation at 0.097 & -549.71 & 8.93 & 0.004 \\
\hline Half-Normal, Cosine (2) adjustments, No Left Truncation, Right Truncation at 0.091 & -542.09 & 16.54 & $<0.001$ \\
\hline Half-Normal, No adjustments, No Left Truncation, Right Truncation at 0.091 & -540.90 & 17.74 & $<0.001$ \\
\hline Half-Normal, No adjustments, No Left Truncation, Right Truncation at 0.097 & -539.39 & 19.24 & $<0.001$ \\
\hline Hazard-Rate, No adjustments, Left Truncation at 0.01 , No Right Truncation & -536.64 & 22.00 & $<0.001$ \\
\hline Hazard-Rate, No adjustments, No Left Truncation, No Right Truncation & -527.91 & 30.72 & $<0.001$ \\
\hline Half-Normal, Cosine (2) adjustments, Left Truncation at 0.01 , No Right Truncation & -520.94 & 37.70 & $<0.001$ \\
\hline Half-Normal, Cosine (2) adjustments, No Left Truncation, No Right Truncation & -512.09 & 46.54 & $<0.001$ \\
\hline Half-Normal, No adjustments, Left Truncation at 0.01 , No Right Truncation & -487.62 & 71.02 & $<0.001$ \\
\hline Half-Normal, No adjustments, No Left Truncation, No Right Truncation & -480.27 & 78.37 & $<0.001$ \\
\hline
\end{tabular}

